\title{
A eficácia de exercícios para disfunção da tuba auditiva
}

\section{The effectiveness of exercises for Eustachian tube dysfunction}

\author{
Camila Leão Sperancini ${ }^{1}$, Damares Plácido Moreira de Souza ${ }^{2}$, Tarcimara Moreira Silva ${ }^{3}$, Camila Queiroz de \\ Moraes Silveira Di Ninno ${ }^{4}$, Márcia Nogueira Amorim5
}

\begin{abstract}
RESUMO
Objetivo: Avaliar a eficácia de exercícios de sopro, sucção e respiração nasal, associados à limpeza nasal e manobra de Valsalva, nas disfunções da tuba auditiva e na prevenção de otite média de repetição. Métodos: Participaram 22 crianças, de ambos os sexos, entre três e seis anos, que apresentavam história de otite média de repetição e, no momento do exame, curvas timpanométricas dos tipos A e C. Tais crianças foram submetidas diariamente aos procedimentos citados durante três meses. Resultados: Ao final do trabalho, das 22 crianças analisadas, 18 apresentaram curvas do tipo A bilateralmente, não apresentando episódios de otite neste intervalo. Conclusão: Na amostra estudada, estes procedimentos mostraram-se eficazes na prevenção da disfunção tubária e otite média de repetição e podem ser utilizados de forma preventiva em crianças de creches.
\end{abstract}

DESCRITORES: Otite média/prevenção \& controle; Tuba auditiva/fisiopatologia; Creches; Prevenção primária; Testes de impedância acústica

\section{INTRODUÇÃO}

No Brasil, a incidência da deficiência auditiva adquirida vem aumentando nos últimos anos, e uma das razões está relacionada à falta de prevenção das principais infecções e doenças contagiosas ${ }^{(1)}$. Isto demonstra o quanto o fator prevenção vem sendo ignorado no dia-a-dia, principalmente, da população carente do nosso país. É de conhecimento científico que no Brasil, pobreza e doença estão intimamente associadas, uma vez que a maioria da população pertence a uma classe sócio-econômica baixa ${ }^{(1)}$.

(1) Responsável técnica pelo setor de Fonoaudiologia da Audiosonic Equipamentos Médicos Ltda. e do Centro de Saúde Ocupacional - Belo Horizonte (MG), Brasil.

(2) Fonoaudióloga do Núcleo de Otorrino BH - Belo Horizonte (MG), Brasil. (3) Pós-graduanda em Cirurgia Geral da Universidade Federal de Minas Gerais - UFMG - Belo Horizonte (MG), Brasil; Professora do Curso de Fonoaudiologia do Unicentro Metodista Izabela Hendrix e da Faculdade de Empreendimentos Administrativos - FEAD - Belo Horizonte (MG), Brasil. (4) Pós-graduanda em Lingüística pela Universidade Federal de Minas Gerais - UFMG - Belo Horizonte (MG), Brasil; Professora do Curso de Fonoaudiologia da Pontifícia Universidade Católica de Minas Gerais - PUCMinas - Belo Horizonte (MG), Brasil.

(5) Mestre em Epidemiologia pela Universidade Federal de Minas Gerais UFMG - Belo Horizonte (MG), Brasil; Professora de Epidemiologia e Bioestatística dos Cursos de Biologia, Nutrição e Enfermagem do Unicentro Metodista Izabela Hendrix e do Curso de Pós-graduação da Universidade São Camilo.

Trabalho realizado com bolsa do PROBIC no Unicentro Metodista Izabela Hendrix - Belo Horizonte (MG), Brasil.

Endereço para correspondência: Camila Queiroz de Moraes Silveira Di Ninno . R. Juvenal de Melo Senra, 51/704, Belo Horizonte - MG, CEP 30330660. E-mail: camilaninno@uol.com.br

Recebido em: 6/3/2006; Aceito em: 8/2/2007
A creche é um local que possui fatores de predisposição a doenças infecto-contagiosas, tendo em vista o íntimo contado entre as crianças ${ }^{(2)}$. A cena do mecanismo de formação da otite média aguda (OMA) é representada por dois atores principais que são a infecção e a disfunção tubária ${ }^{(3-4)}$. Estes são auxiliados por fatores coadjuvantes, como a predisposição a doenças infecciosas e contagiosas da creche e a alergia $^{(5-7)}$, que não só pode ter a mucosa da orelha média como órgão de choque, como também causar edema generalizado da mucosa respiratória, favorecendo a obstrução nasal e tubária, aumentando as secreções da nasofaringe e prejudicando a função mucociliar de drenagem. $\mathrm{O}$ excesso de secreção nasal estimula o ato de fungar, levando secreções à tuba auditiva. Doenças ciliares provocam o acúmulo e estase de secreções. As infecções respiratórias virais podem causar comprometimento ciliar transitório e, assim, facilitar a instalação da $\mathrm{OMA}^{(8)}$.

Obstruções nasais de várias etiologias, hipertrofia adenoideana, traumatismos, estados carenciais alimentares, habitacionais e de higiene, aliados à assistência médica precária contribuem para que se instale a disfunção tubária e OMA.

As infecções de vias aéreas superiores (IVAS) de caráter virótico ou bacteriano, destacando-se bactérias agressoras comuns como Streptococcus pnneumoniae, Haemophilus influenzae, Streptococcus do grupo A, Staphylococcus aureus e Branhamella catarrhalis, atingem a tuba auditiva ${ }^{(9)}$, causando um mau funcionamento desta estrutura, levando a alterações de orelha média. Tais alterações são descritas na literatura como um dos principais fatores causais de otite 
média aguda, crônica e secretora, uma vez que os seus agentes causadores estão associados às infecções respiratórias ${ }^{(9)}$.

A tuba auditiva é uma estrutura que comunica a cavidade timpânica da orelha média à nasofaringe, tendo por função básica permitir que a pressão da orelha média seja equalizada com a pressão do ambiente - ventilação - além de permitir a drenagem das secreções da orelha média para a nasofaringe e protegê-la de secreções contaminadas da nasofaringe ${ }^{(6,10-}$ 11). Mede de 31 a $38 \mathrm{~mm}$ de comprimento, tendo inclinação a 45 graus no adulto e encontrando-se mais horizontalizada na criança $^{(12-13)}$.

Tal estrutura dilata-se temporariamente em situações como o bocejo, deglutição e durante a manobra de Valsalva (método em que se aplica o dedo sobre a asa do nariz, mantendo os lábios vedados e trazendo para a cavidade oral o ar proveniente dos pulmões), permitindo desta forma, que a equalização da pressão e a drenagem da orelha média ocorram. Acredita-se que ela se abra pela contração de um pequeno lábio do tensor do véu palatino, o dilatador da tuba, que afasta a parede lateral membranosa da parede medial, relativamente estacionária, desenrolando a cartilagem durante esse processo. Vale ressaltar que os músculos tensor do véu palatino, elevador do véu palatino, salpingofaríngeo e tensor do tímpano, estão relacionados com a tuba e seus mecanismos de abertura e fechamento(4).

A expressão otite média secretora é utilizada para designar a presença de secreção na cavidade da orelha média, com um tímpano íntegro e sem sinais ou sintomas de inflamação aguda $^{(8)}$; é comum ocorrer após OMA e, com freqüência, a secreção desaparece vagarosamente após o tratamento do processo agudo. As características citológicas são de um processo inflamatório do tipo mucóide, no qual se observa presença de células secretoras e ciliadas com uma lâmina própria espessada, enquanto que, no tipo seroso, há pobreza ou até ausência de células secretoras e ciliadas com diminuição da espessura da lâmina própria ${ }^{(8)}$.

As otites médias com efusão são as causas mais comuns de perda auditiva condutiva em crianças e têm se tornado cada vez mais freqüente nos últimos anos. As causas destas otites são várias, porém, o mau funcionamento da tuba auditiva, ocasionando a não ventilação da orelha média, parece ser a mais aceita delas ${ }^{(5,10)}$. Esta condição permite que o ar fique retido, ocasionando uma diminuição da pressão na orelha média, em relação à pressão atmosférica. Por sua vez, a membrana timpânica sofre retração devido à pressão exercida em sua superfície externa, provocando o enrijecimento da cadeia ossicular. A ausência de ventilação provocada pela pressão negativa na orelha média, leva à formação de líquido em seu interior, podendo resultar em perda auditiva condutiva. Quanto maior o tempo em que a orelha permanecer sem ventilação, maiores serão as mudanças e mais adverso o efeito sobre a ventilação, pois a tuba auditiva encontra-se obstruída por secreções que se tornam cada vez mais espessas. Trata-se, portanto, de um círculo vicioso.

Há um grande interesse no uso de exames de imitância eletroacústica na detecção de alterações de orelha média, em especial, da otite média, na população infantil. Vários fatores contribuem para a utilização desse exame como um instrumento de triagem, uma vez que a imitanciometria é de caráter objetivo, apresenta grande facilidade e rapidez na obtenção de informações precisas ${ }^{(7,14-15)}$, além da relativa ineficácia da audiometria de tom puro, por ser um exame subjetivo $^{(14)}$. Atualmente, a alta prevalência de otite média e a conscientização crescente em relação às consequiências médicas, psicológicas e educacionais que podem resultar da doença da orelha média, têm incentivado a utilização dessa forma de triagem em crianças ${ }^{(15)}$.

Hoje, preocupa-se cada vez mais com o papel dos profissionais de saúde dentro da atuação preventiva, ou seja, trabalhando efetivamente na Saúde Pública e intervindo nas áreas de promoção, proteção e recuperação da saúde aplicada à população.

A creche é um local privilegiado para a atuação em pesquisa e prevenção, por abranger a maioria das crianças de uma mesma faixa etária e região ${ }^{(16)}$.

O conhecimento das características audiológicas e comportamentais de crianças de creche possibilita uma atuação na promoção de um ambiente mais saudável para o seu desenvolvimento integral ${ }^{(17)}$.

De acordo com diversos estudos, há uma alta incidência de otite média que se manifesta por quadros agudos, seguidos de otalgia e diminuição na acuidade auditiva, nas crianças em idade pré-escolar ${ }^{(9,11,17)}$ e a disfunção da tuba auditiva é um importante fator causal ${ }^{(11)}$. Estes episódios repetitivos podem levar a perdas auditivas condutivas em grau leve ou moderado ${ }^{(9,17-19)}$ e afetar o desenvolvimento da fala e da linguagem, com possível prejuízo para o relacionamento social e o aprendizado ${ }^{(9,20-22)}$. A criança se apresenta, muitas vezes, irritada, chorosa, sem apetite, com o sono agitado, além de atraso no desenvolvimento da fala e da linguagem, devido à ausência de respostas aos estímulos sonoros do ambiente ${ }^{(17)}$. É importante ressaltar que três meses de audição precária, nesta idade, equivalem a um período muito longo no desenvolvimento de habilidades relacionadas à linguagem ${ }^{(9)}$.

Com o avanço da idade, é possível perceber uma diminuição destes sintomas ${ }^{(11)}$ e a audição passa a ser flutuante. Por este motivo, alterações do processamento auditivo são comuns nestas crianças, ocasionando déficit de atenção e concentração, alteração de memória a curto e longo prazo e, dificuldade no entendimento da fala em ambientes ruido$\operatorname{sos}^{(17,20)}$.

Para que as crianças pequenas possam ouvir claramente todas as pistas acústicas de uma mensagem, a relação sinal $\mathrm{x}$ ruído deve ser no mínimo de $30 \mathrm{~dB}$. Isso significa que o sinal, ou seja, a fonte sonora deve estar $30 \mathrm{~dB}$ acima do nível de ruído. Tudo isso associado à dificuldade na detecção auditiva causada pela perda de condução sonora que provém da otite média, leva a um cenário perfeito para o surgimento de um atraso no desenvolvimento da aquisição da linguagem.

A orelha média reage aos estímulos agressivos de qualquer natureza com uma resposta tipicamente inflamatória. Como esta reação é multifatorial, seu tratamento tem por objetivo corrigir alterações do mucoperiósteo, no mesmo momento que tenta solucionar as possíveis causas etiológicas. Entre estes fatores etiológicos, o comprometimento da tuba 
auditiva é considerado um dos mais importantes, seja sob a forma de disfunção como de obstrução( ${ }^{(8,11)}$.

A otite média é uma doença dinâmica na qual algumas formas dão lugar a outras ${ }^{(23)}$ e essa sucessão apresenta-se algumas vezes com características clínicas de agudização ou cronificação. Sabendo-se da variabilidade destes estágios não se deve adotar conceitos terapêuticos rígidos ${ }^{(8,11)}$. O tratamento clínico objetiva interromper o processo inflamatório, basicamente pelo uso de antibióticos, mas falta a evidência de que esta profilaxia ou esterilização de infecções seja capaz de modificar a evolução natural da doença ${ }^{(8,11)}$. A escolha desta forma de tratamento deve obedecer ao espectro bacteriano encontrado na região. $\mathrm{O}$ uso de gotas nasais não é justificado devido à impossibilidade destas gotas atingirem a área desejada na tuba auditiva, limitando-se seu uso às obstruções nasais $^{(8)}$. A politzerização e a auto-insuflação são manobras que utilizam pressão aérea para abrir a tuba auditiva, fazendo o ar penetrar na orelha média ${ }^{(24)}$. O resultado imediato nem sempre é obtido, pela dificuldade do método, e porque há uma aceleração na absorção de gás pela mucosa na otite média secretora, além do benefício ser de curta duração ${ }^{(8)}$. O uso de corticóides por curto espaço de tempo visa acelerar a resolução do processo, mas os resultados são contraditórios ${ }^{(8)}$. A falha de um determinado fármaco não deve deixar de considerar a possibilidade de que tenha sido utilizado em uma fase de irreversibilidade da doença, fato que explicaria a contradição das opiniões encontradas na literatura ${ }^{(8)}$.

Há também outros recursos, entre eles o cirúrgico, que é utilizado em alguns casos visando interromper a sequiência evolutiva da doença e ajudar na regressão das alterações do mucoperiósteo, do arejamento e da drenagem da orelha média, ao mesmo tempo em que restaura a audição ${ }^{(8)}$.

Além das seqüelas que a otite média pode causar, o custo do tratamento desta doença, tanto medicamentoso como cirúrgico, é considerado alto para o nosso meio ${ }^{(9)}$.

Assim é que a utilização da reeducação da musculatura peritubária, uma terapia fisiológica voltada para o bom funcionamento da tuba auditiva, é citada recentemente na literatura visando a aeração da orelha média e a prevenção de episódios de otite ${ }^{(25)}$.

A musculatura envolvida na tuba auditiva está direta ou indiretamente relacionada aos músculos das funções estomatognáticas, portanto, alguns autores têm sugerido exercícios miofuncionais como o sopro, a sucção, a respiração nasal, a mastigação e a deglutição, os quais, associados a uma adequada limpeza nasal e à manobra de Valsalva, exercitariam a musculatura envolvida na tuba auditiva ${ }^{(4,25-27)}$. Deste modo, haveria uma melhora da drenagem de secreções e aeração da orelha média. A aplicação desta proposta, em um caso, mostrou resultados positivos possibilitados pela avaliação da orelha média após um mês do início da terapia ${ }^{(25)}$.

O presente estudo teve por objetivo avaliar a eficácia de exercícios de sopro, sucção e respiração nasal, associados à limpeza nasal e à manobra de Valsalva, na disfunção da tuba auditiva e na prevenção de otites médias de repetição, em um número maior de crianças de uma instituição em Belo Horizonte, como uma proposta de trabalho a ser adotado em sua rotina.

\section{MÉTODOS}

O presente estudo foi aprovado pelo Comitê de Ética em Pesquisa da Universidade Federal de Minas Gerais (protocolo 099/02). Todos os sujeitos envolvidos concordaram em participar desta pesquisa, tendo seus responsáveis legais, assinado um termo de consentimento livre e esclarecido.

A pesquisa foi realizada em uma creche conveniada com a Prefeitura de Belo Horizonte, que atendia a 160 crianças entre um e seis anos de idade e onde existia um programa de estágio para alunos do curso de Fonoaudiologia do Unicentro Metodista Izabela Hendrix, com ênfase na promoção e prevenção da saúde fonoaudiológica.

Em um estudo preliminar, realizado pelos autores deste estudo ${ }^{(28)}$, aplicou-se um questionário aos pais ou responsáveis por todas as crianças entre três e seis anos de idade que freqüentavam a creche, em um total de 111 crianças, sendo $45 \%$ do sexo feminino e $55 \%$ do sexo masculino, enfocando a presença de queixas auditivas e otológicas. Posteriormente, ainda neste mesmo estudo, realizou-se uma avaliação otorrinolaringológica e os exames de otoscopia e imitanciometria em todas estas crianças. Com relação aos achados obtidos por meio dos questionários aplicados aos pais ou responsáveis, $84 \%$ relataram presença de queixas otológicas e/ ou auditivas em seus filhos, sendo que destes, $64 \%$ referiram quadros de otites freqüentes, $20 \%$ dúvidas quanto à acuidade auditiva e $47 \%$ respiração oral. Além disso, $15 \%$ das crianças apresentaram rolha de cera, $9 \%$ retração de membrana, $5 \%$ otite média aguda e $63 \%$ curva do tipo A, $14,5 \%$ curva do tipo B e $22,5 \%$ curva do tipo C.

Selecionaram-se para participar da presente pesquisa todas as crianças pertencentes à faixa etária entre três e seis anos, de ambos os sexos, que no estudo anterior tinham apresentado história clínica de otites de repetição e, ao exame de imitanciometria, curvas timpanométricas do tipo A ou do tipo $\mathrm{C}$.

Excluiu-se desta pesquisa, além das crianças com curva timpanométrica do tipo $\mathrm{B}$, crianças com otite externa, perfuração de membrana timpânica e/ou presença de processos patológicos crônicos em pelo menos uma orelha, e aquelas que ao exame clínico apresentaram infecções de vias aéreas superiores e ou história de cirurgia otológica prévia. Os casos com acúmulo de cerume no meato acústico externo foram submetidos à retirada do mesmo, pela médica otorrinolaringologista, co-autora do trabalho, antes da realização da imitanciometria.

Desta forma, de acordo com os critérios de inclusão e exclusão expostos anteriormente, das 111 crianças participantes do estudo anterior, 22 constituíram a amostra do presente estudo.

Para a realização deste, os equipamentos utilizados foram um otoscópio Welch Allyn modelo 728 e um imitanciômetro modelo $A Z-7$, além de materiais relacionados à biossegurança. Para a realização dos exercícios oromiofuncionais e dos procedimentos de limpeza nasal e manobra de Valsalva, utilizou-se soro fisiológico, luvas e seringas de cinco ml descartáveis, lenços de papel, balões, línguas de sogra e canudos descartáveis do tipo fino e longo. 
Os pais ou responsáveis pelas crianças selecionadas receberam inicialmente orientações relacionadas à pesquisa, seus objetivos, importância e procedimentos a serem realizados em casa.

Por um período de três meses, foram realizados, três vezes ao dia, os seguintes exercícios/procedimentos: limpeza nasal com soro físiológico, sopro de balão pela boca e de língua de sogra em ambas as narinas alternadamente, sucção de água com canudo e manobra de Valsalva. Tais exercícios/ procedimentos foram realizados uma vez ao dia na creche, pelos pesquisadores e mais duas vezes ao dia em casa, pelos pais ou responsáveis, previamente orientados.

O procedimento de limpeza nasal com soro fisiológico, previamente à realização dos demais exercícios/procedimentos que visavam à estimulação da musculatura envolvida na abertura da tuba auditiva, conforme proposto por outros estu$\operatorname{dos}^{(4)}$, foi realizado com o intuito para fluidificar as secreções e melhorar a aeração nasal, evitando que durante os exercícios as secreções fossem direcionadas para a orelha média.

O exame imitanciométrico foi repetido quatro vezes ao longo deste estudo. A primeira foi ao término do primeiro mês do início da realização dos exercícios/procedimentos; outra ao final do segundo mês, outra ainda ao término do terceiro mês e, por fim, o exame foi novamente realizado após seis meses do término do trabalho, apenas nas crianças que haviam apresentado uma curva timpanométrica do tipo A.

As três primeiras avaliações imitanciométricas tiveram o intuito de testar a eficácia dos exercícios/procedimentos propostos nas disfunções da tuba auditiva, levando à minimização de suas conseqüências. A última avaliação teve por objetivo verificar se seis meses após o término da realização dos exercícios/procedimentos, as crianças mantinham o mesmo padrão de curva timpanométrica (tipo A).

Ao final do estudo, os pais/responsáveis novamente participaram de uma reunião com as pesquisadoras, a fim de que fossem apresentados os resultados do trabalho e fosse efetuada uma pergunta se eles haviam notado, com a realização do trabalho, alguma mudança em seus filhos, no que dizia respeito aos aspectos respiratórios e/ou otológicos.

Os resultados foram analisados em um pacote estatístico EpiInfo 6.4 para comparação entre frequiências.

\section{RESULTADOS}

$\mathrm{Na}$ presente pesquisa, estudou-se 22 crianças, sendo 5 (23\%) com idade de 3 anos, $12(54,55 \%)$ com idade de 4 anos, $3(13,5 \%)$ com idade de 5 anos e $2(9 \%)$ com idade de 6 anos (Tabela 1). Treze crianças $(56 \%)$ eram do sexo masculino e 9 (44\%) do sexo feminino (Tabela 2).

O trabalho foi realizado durante três meses, sendo que no início a curva timpanométrica do tipo $\mathrm{C}$ era a mais prevalente, presente em $13(59 \%)$ das crianças e a tipo A em 9 (41\%).

Nas Tabelas 3 e 4 pode-se analisar os resultados obtidos após os três meses de intervenção junto às crianças. Observou-se uma melhora importante nos quadros de disfunção tubária, visto que $18(82 \%)$ das 22 crianças apresentaram curva timpanométrica do tipo A.

A análise da Figura 1 permite a comparação dos resultados antes e após três meses do início da realização dos exercícios/procedimentos. De acordo com esta análise, a curva do tipo A, presente no início em 9 (41\%) dos casos, passou a estar presente em 18 (82\%). A curva do tipo C, antes presente em $13(59 \%)$ dos casos, passou a ser encontrada em apenas duas (9\%). Duas crianças $(9 \%)$ evoluíram para a curva do tipo B.

Após seis meses do término dos exercícios/procedimentos, o exame imitanciométrico foi repetido em 14 das 18 crianças que apresentaram curva do tipo A. Destas 14 crianças, $12(85 \%)$ mantiveram o mesmo padrão de curva (tipo A) e $2(15 \%)$ apresentaram curva do tipo $C$, sugerindo que a

Tabela 1. Curva timpanométrica das crianças da amostra no início dos trabalhos, segundo idade

\begin{tabular}{|c|c|c|c|c|c|c|c|c|}
\hline \multirow{3}{*}{$\begin{array}{l}\text { Idade } \\
\text { (anos) }\end{array}$} & \multicolumn{6}{|c|}{ Tipo de Curva } & \multirow{2}{*}{\multicolumn{2}{|c|}{ Total }} \\
\hline & \multicolumn{2}{|c|}{$A$} & \multicolumn{2}{|c|}{ B } & \multicolumn{2}{|c|}{$\mathrm{C}$} & & \\
\hline & $\mathrm{n}$ & $(\%)$ & $\mathrm{n}$ & (\%) & $n$ & (\%) & $n$ & $(\%)$ \\
\hline 3 & 1 & (20) & 0 & - & 4 & (80) & 05 & $(23,0)$ \\
\hline 4 & 5 & (42) & 0 & - & 7 & (58) & 12 & $(54,5)$ \\
\hline 5 & 2 & (67) & 0 & - & 1 & (33) & 03 & $(13,5)$ \\
\hline 6 & 1 & (50) & 0 & - & 1 & (50) & 02 & $(9,0)$ \\
\hline Total & 9 & (41) & 0 & (0) & 13 & (59) & 22 & (100) \\
\hline
\end{tabular}

Tabela 2. Curva timpanométrica das crianças da amostra no início dos trabalhos, segundo sexo

\begin{tabular}{|c|c|c|c|c|c|c|c|c|}
\hline \multirow{3}{*}{ Sexo } & \multicolumn{6}{|c|}{ Tipo de Curva } & \multirow{2}{*}{\multicolumn{2}{|c|}{ Total }} \\
\hline & \multicolumn{2}{|c|}{$A$} & \multicolumn{2}{|c|}{ B } & \multicolumn{2}{|c|}{ C } & & \\
\hline & $\mathrm{n}$ & $(\%)$ & $\mathrm{n}$ & $(\%)$ & $\mathrm{n}$ & $(\%)$ & $\mathrm{n}$ & $(\%)$ \\
\hline Feminino & 4 & (44) & 0 & - & 5 & (56) & 09 & (44) \\
\hline Masculino & 5 & (38) & 0 & - & 8 & (62) & 13 & (56) \\
\hline Total & 9 & (41) & 0 & (0) & 13 & (59) & 22 & (100) \\
\hline
\end{tabular}


Tabela 3. Curva timpanométrica das crianças da amostra após três meses de trabalho, segundo idade

\begin{tabular}{|c|c|c|c|c|c|c|c|c|}
\hline \multirow{3}{*}{$\begin{array}{l}\text { Idade } \\
\text { (anos) }\end{array}$} & \multicolumn{6}{|c|}{ Tipo de Curva } & \multirow{2}{*}{\multicolumn{2}{|c|}{ Total }} \\
\hline & \multicolumn{2}{|c|}{$A$} & \multicolumn{2}{|c|}{$\mathrm{B}$} & \multicolumn{2}{|c|}{ C } & & \\
\hline & $\mathrm{n}$ & $(\%)$ & $\mathrm{n}$ & $(\%)$ & $\mathrm{n}$ & $(\%)$ & $\mathrm{n}$ & $(\%)$ \\
\hline 3 & 3 & $(60)$ & 0 & & 2 & $(40)$ & 05 & $(23,0)$ \\
\hline 4 & 11 & (92) & 1 & (8) & 0 & - & 12 & $(54,5)$ \\
\hline 5 & 2 & (67) & 1 & (33) & 0 & - & 03 & $(13,5)$ \\
\hline 6 & 2 & (100) & 0 & & 0 & - & 02 & $(9,0)$ \\
\hline Total & 18 & (82) & 2 & (9) & 2 & (9) & 22 & (100) \\
\hline
\end{tabular}

Tabela 4. Curva timpanométrica das crianças da amostra após três meses de trabalho, segundo sexo

\begin{tabular}{|c|c|c|c|c|c|c|c|c|}
\hline \multirow{3}{*}{ Sexo } & \multicolumn{6}{|c|}{ Tipo de Curva } & \multirow{2}{*}{\multicolumn{2}{|c|}{ Total }} \\
\hline & \multicolumn{2}{|c|}{$A$} & \multicolumn{2}{|c|}{ B } & \multicolumn{2}{|c|}{ C } & & \\
\hline & $\mathrm{n}$ & $(\%)$ & $\mathrm{n}$ & $(\%)$ & $\mathrm{n}$ & $(\%)$ & $\mathrm{n}$ & $(\%)$ \\
\hline Feminino & 7 & (78) & 0 & - & 2 & (22) & 09 & (44) \\
\hline Masculino & 11 & (85) & 2 & (15) & 0 & - & 13 & (56) \\
\hline Total & 18 & (82) & 2 & (9) & 2 & (9) & 22 & (100) \\
\hline
\end{tabular}

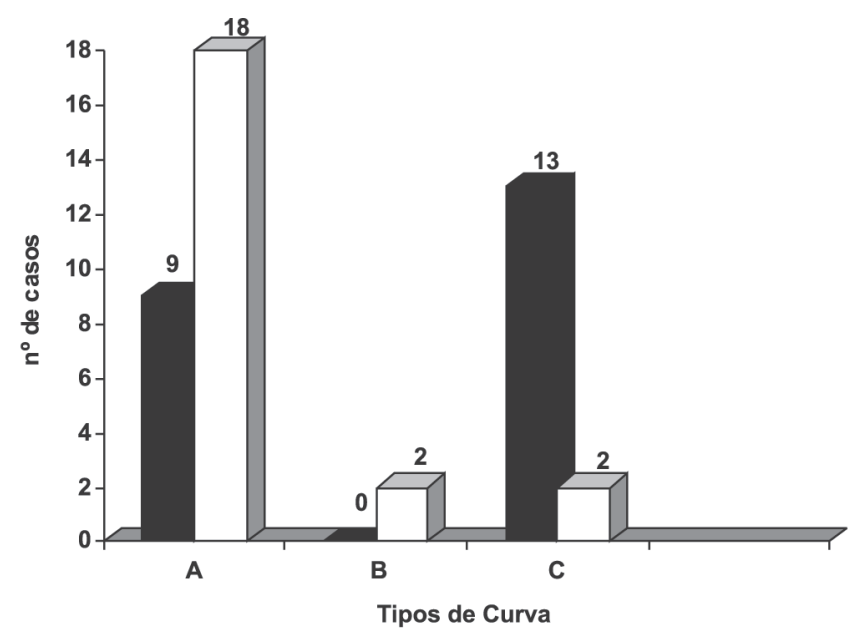

Início $\square$ Após 3 meses

Figura 1. Comparação das curvas timpanométricas no início e término do trabalho

grande maioria das crianças manteve o bom funcionamento da tuba auditiva. Das 18 crianças que deveriam ter realizado esta última avaliação, quatro não retornaram para o exame por terem saído da creche e, com isso, não terem sido localizadas.

Ao final do trabalho, em reunião com os pais e/ou responsáveis pelas crianças participantes, ao serem indagados sobre modificações nos aspectos respiratório e otológico, encontradas nas crianças com a realização deste trabalho, os mesmos foram unânimes em afirmar que durante o período de realização do estudo, as crianças não apresentaram queixas de otalgia, houve menor ocorrência de coriza e diminuição do ronco/ruído respiratório durante o sono.

\section{DISCUSSÃO}

A partir dos resultados obtidos nesta pesquisa, algumas considerações devem ser destacadas.

Inicialmente, deve-se ressaltar que existem ainda poucos estudos nesta área, havendo necessidade de ampliar os conhecimentos sobre o tema proposto e suas aplicações.

$\mathrm{O}$ uso de procedimentos combinados, como o levantamento do histórico das crianças e a realização dos exames de otoscopia e imitanciometria utilizados neste estudo, tem sido apontado como o melhor na identificação em creches de casos com alterações otológicas e audiológicas ${ }^{(17)}$.

Casos com disfunção tubária (curva do tipo C) prevaleceram entre as crianças de três e quatro anos de idade, no início do trabalho, e entre as crianças de três anos, no final do mesmo, estando de acordo com o que foi descrito na literatura pesquisada, ou seja, que os quadros de otites médias de repetição e IVAS são mais comuns nos primeiros anos e tendem a diminuir com o avanço da idade ${ }^{(17,29)}$.

O sexo masculino apresentou maior número de casos de disfunção tubária no início da pesquisa, o que não pôde ser verificado no final do estudo. Alguns autores encontraram maior prevalência de otites em crianças moradoras em cidades, de nível socioeconômico baixo e do sexo masculino ${ }^{(2)}$.

A comparação entre os resultados dos exames revelou que no início, a curva timpanométrica do tipo $\mathrm{C}$ representava a maioria dos casos e, ao final do estudo, a curva do tipo A prevaleceu entre as demais, demonstrando assim, a contribuição dos procedimentos propostos no tratamento das disfunções tubárias e, conseqüentemente, na prevenção das otites médias de repetição, estando de acordo com outros estudos realiza$\operatorname{dos}^{(4,25-27)}$. No entanto, pela impossibilidade de acompanhar um grupo controle, sugere-se que sejam realizados novos trabalhos nesta área, a fim de confirmar em outras populações, o 
benefício obtido com estes procedimentos.

As informações obtidas ao final do estudo com os pais/ responsáveis sugerem que o trabalho realizado, além de ter melhorado a função tubária e espaçar ou prevenir os episódios de otite, conforme esperado, diminuiu também a ocorrência de IVAS neste período, com conseqüente melhora na qualidade do sono das crianças.

Apesar de a presente pesquisa ter sido realizada durante o período de inverno, as condições climáticas e suas conseqüências, apontadas como desfavoráveis em outros estudos ${ }^{(4)}$, não interferiram na obtenção de respostas positivas à intervenção fonoaudiológica junto a este grupo de indivíduos.

Com a análise dos dados obtidos, pode-se constatar que por meio de procedimentos simples e utilizando recursos acessíveis, foi possível, neste grupo de crianças e durante este período de estudo, prevenir episódios repetitivos de otites, contribuindo assim para a melhoria do desenvolvimento e qualidade de vida das mesmas. Visto que a atuação preventiva dos profissionais da saúde é de fundamental importância na busca e utilização de medidas que visem ao bem estar da população, foi proposta a inclusão de tais procedimentos na rotina diária das crianças da creche.
Gostaríamos, ainda, de ressaltar a importância do trabalho do fonoaudiólogo em parceria com o médico otorrinolaringologista para o sucesso da intervenção junto a pacientes que apresentam disfunção tubária, visando à prevenção de episódios de otite e garantindo melhor qualidade de vida aos mesmos.

\section{CONCLUSÃO}

$\mathrm{Na}$ amostra estudada, os exercícios de sopro, sucção e respiração nasal, associados aos procedimentos de limpeza nasal e manobra de Valsalva, mostraram-se eficazes para a melhora da função tubária e prevenção da otite média de repetição, durante o período do estudo, e podem ser utilizados de forma preventiva em crianças de creches.

\section{AGRADECIMENTOS}

Agradecemos às fonoaudiólogas Marilza Ribeiro e Rebeca Concetta Godinho pela dedicação na realização dos exercícios com as crianças e à Creche Cavalinho de Pau que nos abriu todas as portas para que pudéssemos realizar este trabalho.

\begin{abstract}
Purpose: To assess the effectiveness of blowing, suction, and nasal breathing exercises, associated with nose cleaning and Valsalva's maneuver, for Eustachian tube dysfunctions and preventing recurrent otitis media. Methods: Twenty-two children of both genders, with ages between three and six years, who had a history of recurrent otitis media and, at the moment of the exam, types A and C tympanometric curves participated in the study. The subjects were submitted daily to the above-mentioned procedures for 3 months. Results: At the end of the study, the last immitance audiometry of the 22 analyzed children showed that 18 of them had bilateral type A curves and no otitis episodes during this interval. Conclusion: In the studied sample, these procedures proved to be effective for preventing tube dysfunction and recurrent otitis media, and may be used preventively in children at day care centers.
\end{abstract}

KEYWORDS: Otitis media; Eustachian tube; Child day care centers; Primary prevention; Acoustic impedance tests

\title{
REFERÊNCIAS
}

1. Lichtig I. Considerações sobre a situação da deficiência auditiva na infância no Brasil. In: Lichtig I, Carvalho RMM. Audição: abordagens atuais. São Paulo: Pró-Fono; 1997. p. 3-22.

2. Paradise JL, Rockette HE, Colborn DK, Bernard BS, Smith CG, KursLasky M, Janosky JE. Otitis media in 2253 Pittsburgh-area infants: prevalence and risk factors during the first two years of life. Pediatrics. 1997;99(3):318-33

3. van Heerbeek N, Ingels KJ, Rijkers GT, Zielhuis GA. Therapeutic improvement of Eustachian tube function: a review. Clin Otolaryngol Allied Sci. 2002;27(1):50-6.

4. Consoni FMC, Croscato JCF, Malveste MC. Perfil analítico da intervenção fonoaudiológica em pacientes com disfunção da tuba auditiva. Rev Soc Bras Fonoaudiol. 2003;8(2):49-57.

5. Nguyen LH, Manoukian JJ, Tewfik TL, Sobol SE, Joubert P, Mazer BD, et al. Evidence of allergic inflammation in the middle ear and nasopharynx in atopic children with otitis media with effusion. J Otolaryngol. 2004;33(6):345-51.
6. Grimmer JF, Poe DS. Update on eustachian tube dysfunction and the patulous eustachian tube. Curr Opin Otolaryngol Head Neck Surg. 2005;13(5):277-82.

7. Lazo-Sáenz JG, Galván-Aguilera AA, Martínez-Ordaz VA, VelascoRodríguez VM, Nieves-Rentería A, Rincón-Castañeda C. Eustachian tube dysfunction in allergic rhinitis. Otolaryngol Head Neck Surg. 2005;132(4):626-9.

8. Costa SS, Cruz OLM. Introdução às Otites Médias. In: Costa SS, Cruz OLM, Oliveira JAA, organizadores. Otorrinolaringologia: princípios e práticas. Porto Alegre: Artes Médicas; 1994. p. 120-2.

9. Bogar P, Santoro PP, Medeiros IRT, Bento RF, Marone SAM. Otite média secretora: perfil terapêutico por uma amostra de especialistas. Rev Bras Otorrinolaringol. 1998;64(2):127-35.

10. Straetemans M, van Heerbeek N, Tonnaer E, Ingels KJ, Rijkers GT, Zielhuis GA. A comprehensive model for the aetiology of otitis media with effusion. Med Hypotheses. 2001;57(16):784-91. 
11. Bluestone CD. Studies in otitis media: Children's Hospital of PittsburghUniversity of Pittsburgh progress report - 2004. Laryngoscope. 2004;114(11 Pt 3 Suppl 105):1-26.

12. Sadler-Kimes D, Siegel MI, Todhunter JS. Age-related morphologic differences in the components of the eustachian tube/middle ear system. Ann Otol Rhinol Laryngol. 1989;98(11):854-8.

13. Ishijima K, Sando I, Balaban C, Suzuki C, Takasaki K. Length of the eustachian tube and its postnatal development: computer-aided threedimensional reconstruction and measurement study. Ann Otol Rhinol Laryngol. 2000;109(6):542-8.

14. Bluestone CD, Beery QC, Paradise JL. Audiometry and tympanometry in relation to middle ear effusions in children. Laryngoscope. 1973;83(4):594-604.

15. Beery QC, Bluestone CD, Cantekin EI. Otologic history, audiometry and tympanometry as a case finding procedure for school screening. Laryngoscope. 1975;85(12 Pt 1):1976-85.

16. Cavalheiro MTP. Trajetórias e possibilidades de atuação do fonoaudiólogo na escola. In: Lagrotta MGM, César CPHAR. A Fonoaudiologia nas instituições. São Paulo: Lovise; 1997. p. 81-8.

17. Hubig DOC. Caracterização do comportamento de crianças de risco para otites médias: ouvindo educadores de creche. Rev Soc Bras Fonoaudiol. 2002;7(1):5-15.

18. Brooks DN. Otitis media and child development. Design factors in the identification and assessment of hearing loss. Ann Otol Rhinol Laryngol Suppl. 1979;88(5 Pt 2 Suppl 60):29-47.

19. Fria TJ, Cantekin EI, Eichler JA. Hearing acuity of children with otitis media with effusion. Arch Otolaryngol. 1985;111(1):10-6.

20. Schilder AG, Snik AF, Straatman H, van den Broek P. The effect of otitis media with effusion at preschool age on some aspects of auditory perception at school age. Ear Hear. 1994;15(3):224-31.
21. Feldman HM, Dollaghan CA, Campbell TF, Colborn DK, Janosky J, Kurs-Lasky M, et al. Parent-reported language skills in relation to otitis media during the first 3 years of life. J Speech Lang Hear Res. 2003;46(2):273-87.

22. Dobie RA, Berlin CI. Influence of otitis media on hearing and development. Ann Otol Rhinol Laryngol Suppl. 1979;88(5 Pt 2 Suppl 60):48-53.

23. Goycoolea MV, Ruah CB, Bequer N. Otitis media: the pathogenesis approach. General surgical approach based on pathogenesis. An overall approach. Otolaryngol Clin North Am. 1991;24(4):957-66.

24. Renvall U. Reduction of artificially increased middle ear air pressure. In: Lim DJ, editor. Recent advances in otitis media with effusion. Philadelphia: BC Decker; 1984.

25. Jorge C. Terapia da reeducação tubária: uma proposta de apoio ao tratamento das otites médias crônicas. In: Congresso Brasileiro de Fonoaudiologia; 2001 Set 26-29; Guarapari. Anais. São Paulo; 2001.

26. Faria ER, Macarini GC. Intervenção fonoaudiológica na profilaxia da disfunção tubária [monografia]. Franca: Universidade de Franca; 1998.

27. Soares RRL, Britto AT. Aplicação de procedimentos terapêuticos na profilaxia da desobstrução tubária - um estudo de caso [monografia]. Franca: Universidade de Franca; 2001

28. Sperancini CL, Souza D, Di Ninno CQMS, Silva TM. Levantamento das condições da orelha média de crianças de 3 a 6 anos da creche "Cavalinho de pau". In: Congresso Brasileiro de Fonoaudiologia; 2002 Set 26-28; Belo Horizonte. Anais. São Paulo; 2002.

29. Zielhuis GA, Rach GH, van den Bosch A, van den Broek P. The prevalence of otitis media with effusion: a critical review of the literature. Clin Otolaryngol Allied Sci. 1990;15(3):283-8. 